\title{
Cationic Polymerization of Vinyl Monomers Initiated by Carbon Black Surface
}

\author{
Norio TsuboKawA, Naoki TAKedA, and Tetsuo IwASA \\ Department of Applied Chemistry, Faculty of Engineering, \\ Niigata University, Ikarashi 2-8050, Niigata 950-21, Japan.
}

(Received March 31, 1981)

\begin{abstract}
The polymerization of vinyl monomers initiated by carboxyl groups on the surface of carbon black has been investigated. Channel blacks were found capable of initiating the cationic polymerization of vinyl monomers such as vinyl ethers, indene, and acenaphthylene but unable to initiate that of styrene and vinylpyridines. The rate of polymerization, $R_{\mathrm{p}}$, of isobutyl vinyl ether (IBVE) initiated by Carbolac 1 in polar solvent $\left(\mathrm{CCl}_{4} / \mathrm{C}_{6} \mathrm{H}_{5} \mathrm{NO}_{2}=50 \mathrm{v} / \mathrm{v} \%\right)$ is expressed by the following equation: $R_{\mathrm{p}}=$ const [IBVE] ${ }^{2}$ [Carbolac 1]. The features are explained on the basis of a conventional cationic mechanism. The overall activation energy is estimated to be 27 $\mathrm{kcal} \mathrm{mol}^{-1}$. This value is larger than that of the polymerization of IBVE in nonpolar solvent $\left(\mathrm{CCl}_{4}\right)$. In addition, during polymerization, the polymer is grafted onto the surface of carbon black and the carbon black obtained from the reaction gives a stable colloidal dispersion in good solvents for the polymer. The grafting sites of the polymer were found to be carboxyl groups present on the surface.

KEY WORDS Carbon Black / Cationic Polymerization / Cationic Polymerization Catalyst / Vinyl Ether / Indene / Acenaphthylene / Graft Polymerization /
\end{abstract}

The polymerization of olefins catalyzed by carbon black has been reported by Given et al. ${ }^{1}$ However, a catalytic effect was observed only after heating the carbon black from 100 to $115^{\circ} \mathrm{C}$ in vacuo for 20 to $40 \mathrm{~h}$. The predominant product of the reaction was dimer. ${ }^{1}$

On the other hand, we reported the cationic polymerization of $N$-vinylcarbazole (NVC) initiated by furnace black surface at relatively high temperatures $\left(50-80^{\circ} \mathrm{C}\right) .^{2}$ Furthermore, Ohkita et al. showed that phenolic hydroxyl groups on the surface of furnace black have the ability to initiate the polymerization of NVC. ${ }^{3}$

We recently found that carboxyl groups on the surface of color channel black can initiate the cationic polymerization of isobutyl vinyl ether (IBVE),${ }^{4} \quad \alpha$-methylstyrene, ${ }^{5} \quad$ and $\quad N$-vinyl-2pyrrolidone (NVPD) ${ }^{6}$ even below room temperature. In addition, it was found that the rate of polymerization $\left(R_{\mathrm{p}}\right)$ of IBVE initiated by Carbolac 1 in nonpolar solvent $\left(\mathrm{CCl}_{4}\right)$ can be expressed by the following equation ${ }^{4}$ :

$$
R_{\mathrm{p}}=\text { constant }[\mathrm{IBVE}][\text { Carbolac } 1]^{2} \text {. }
$$

In this paper, the initiating activity of channel black for cationic polymerization of vinyl monomers having different $e$ values is reported. Moreover, the kinetic order with respect to carbon black and IBVE in polar solvent is compared with that in nonpolar solvent. On the basis of these results, the initiation mechanism of the polymerization is discussed. In addition, the graft polymerization of NVPD onto carbon black and the grafting sites of the polymer on the surface are studied.

\section{EXPERIMENTAL}

\section{Materials}

For carbon black, FW 200 (Specific surface area: $\left.460 \mathrm{~m}^{2} \mathrm{~g}^{-1}\right)$, Carbolac $1 \quad\left(839.2 \mathrm{~m}^{2} \mathrm{~g}^{-1}\right)$, and Neospectra II $\left(906 \mathrm{~m}^{2} \mathrm{~g}^{-1}\right)$ were used. The carbon blacks were dried in vacuo at $110^{\circ} \mathrm{C}$ prior to use. The content of the carboxyl groups on the surface of FW 200, Carbolac 1, and Neospectra II was 0.61, 0.54, and 0.40 meq $^{-1}$, respectively. ${ }^{4}$

Ethyl vinyl ether (EVE), n-butyl vinyl ether ( $n \mathrm{BVE}$ ), and IBVE (from Tokyo Kasei Co. Ltd.) 
were washed with an aqueous solution of weak alkali, and then dried over potassium hydroxide followed by refluxing on metallic sodium and fractionally distilled. Indene (from Eastman Kodak Co.) was stirred overnight with $6 \mathrm{~N}$ hydrochloric acid, refluxed with $40 \%$ sodium hydroxide for $2 \mathrm{~h}$, dried over magnesium sulfate, and then over calcium hydride. It was then distilled under nitrogen before use. Acenaphthylene was recrystallized from ethanol. Styrene, 2-vinylpyridine, 4-vinylpyridine, and NVPD were also purified by the usual methods. Nitrobenzene, chlorobenzene, and carbon tetrachloride were purified and distilled by a general method.

\section{Procedure of Polymerization}

Freshly distilled monomer, carbon black, and solvent were introduced into a $100 \mathrm{ml}$ tear-drop type flask. The polymerization was conducted under dry nitrogen and the reaction mixture was stirred at constant rate with a magnetic stirrer. After a certain period of time, the content of the flask was poured into a large amount of methanol to precipitate the polymer and carbon black. In the case of EVE and NVPD, the polymerization was brought to a stop by introducing ammoniacal methanol or $N, N$ dimethylformamide. The monomer and solvent were then pumped off at room temperature.

\section{Isolation of Carbon Black from Polymerization Product}

The polymerization product containing carbon black and NVPD-homopolymer was dispersed in methanol and centrifuged at $10^{4} \mathrm{rpm}$ for $4 \mathrm{~h}$. The carbon black precipitated was extracted with methanol, using a Soxhlet apparatus for $50 \mathrm{~h}$. The amount of poly(NVPD) grafted onto the surface was determined by a semi-micro-Kjeldahl procedure. $^{7}$

\section{RESULTS AND DISCUSSION}

\section{Polymerization of Vinyl Monomers Initiated by Carbon Black}

The polymerization of IBVE, $n \mathrm{BVE}$, and EVE in the presence of Carbolac 1 is shown in Figure 1. In the absence of carbon black, no polymerization could be detected. In the presence of Carbolac 1, however, the polymerization of these monomers proceeded as shown in Figure 1, in which the effect.

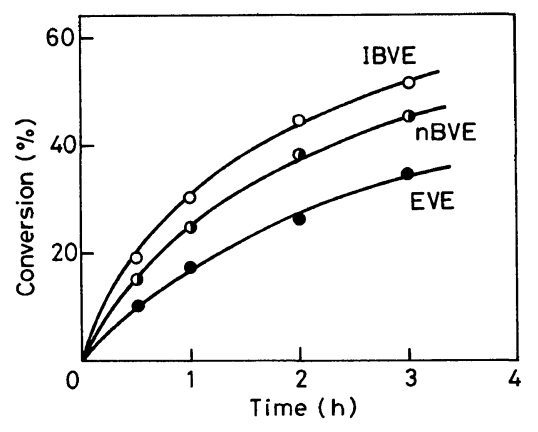

Figure 1. Polymerization of vinyl ethers initiated by Carbolac 1: Carbolac 1, $0.1 \mathrm{~g}$; monomer, $3.8 \mathrm{moll}^{-1}$; solvent, $\mathrm{CCl}_{4}$; total volume, $20.0 \mathrm{ml} ; 20^{\circ} \mathrm{C}$.

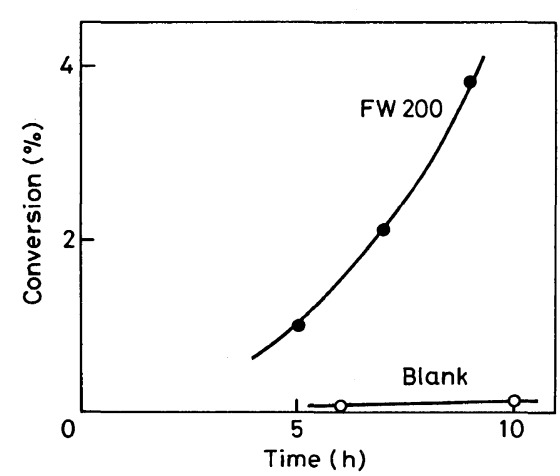

Figure 2. Bulk polymerization of indene initiated by FW 200: FW 200, $1.0 \mathrm{~g}$; indene, $10.0 \mathrm{ml} ; 50^{\circ} \mathrm{C}$.

of Carbolac 1 as an initiator is clearly shown. In the previous paper, it was indicated that the carboxyl groups on the surface of carbon black play an important role in initiating the polymerization of IBVE and both quinonic oxygen and phenolic hydroxyl groups are ineffective for this initiation. ${ }^{4}$

The rate of polymerization was found to decrease in the order: IBVE $>n \mathrm{BVE}>\mathrm{EVE}$. This order is in agreement with that of the comparative polymerizability of vinyl ethers with boron fluoride catalyst. ${ }^{8}$

Using FW 200, which has a high initiating activity for cationic polymerization of $\mathrm{IBVE}^{4}{ }^{4}$ the polymerization of indene and acenaphthylene was examined. Figure 2 shows the results of the polymerization of indene initiated by FW 200. Although low conversion was obtained in the absence of carbon black, the polymerization of indene was accelerated by FW 200 .

Furthermore, using $3.0 \mathrm{~g}$ of acenaphthylene, $0.5 \mathrm{~g}$ 
Table I. Initiating activity of channel black for the cationic polymerization of various monomers

\begin{tabular}{lcc}
\multicolumn{1}{c}{ Monomer } & $e$ value $^{9}$ & Polymerization \\
\hline Isobutyl vinyl ether & -1.770 & $\bigcirc^{4}$ \\
$N$-vinylcarbazole & -1.400 & $\bigcirc^{2,3}$ \\
$\alpha$-Methylstyrene & -1.270 & $\bigcirc^{5}$ \\
$n$-Butyl vinyl ether & -1.200 & $\bigcirc$ \\
Ethyl vinyl ether & -1.170 & $\bigcirc$ \\
$N$-vinyl-2-pyrrolidone & -1.140 & $\bigcirc^{6}$ \\
Indene & -1.030 & $\bigcirc$ \\
2-Methyl-1-propene & -0.960 & $\mathrm{Dimer}^{1}$ \\
Acenaphthylene & -0.800 & $\bigcirc^{\mathrm{a}}$ \\
Styrene & -0.800 & $\times$ \\
2-Vinylpyridine & -0.500 & $\times$ \\
4-Vinylpyridine & -0.280 & $\times$ \\
\hline
\end{tabular}

${ }^{\text {a }}$ Acenaphthylene, $3.0 \mathrm{~g}$; FW 200, $0.5 \mathrm{~g} ; \mathrm{C}_{6} \mathrm{H}_{5} \mathrm{Cl}, 5.0 \mathrm{ml}$; $60^{\circ} \mathrm{C}$.

of FW 200 , and $5.0 \mathrm{ml}$ of chlorobenzene, polymerization was studied at $60^{\circ} \mathrm{C}$. It was found that polymerization was initiated by FW 200 and the yield of polymer after $6 \mathrm{~h}$ was $5.2 \%$.

Similar polymerizations of indene or acenaphthylene were observed in the presence of other channel blacks.

In addition, bulk polymerization of styrene, 2vinylpyridine, and 4-vinylpyridine were carried out at $50^{\circ} \mathrm{C}$ for $6 \mathrm{~h}$. It was apparent that channel black had no ability to initiate the cationic polymerization of these monomers under the above conditions.

The initiating activity of carboxyl groups on the surface to bring about the cationic polymerization of various vinyl monomers is summarized in Table I. From these results, it is concluded that carbon black has no initiating activity for the cationic polymerization of vinyl monomers whose $e$ values are larger than $c a$. -0.8 .

\section{Kinetic Study of the Polymerization of IBVE} Initiated by Carbolac 1 in Polar Solvent

To gain further insight into carbon blackinitiated polymerization, a kinetic study of the polymerization was carried out. In the previous paper, we reported that the polymerization rate of IBVE initiated by Carbolac 1 in a nonpolar solvent $\left(\mathrm{CCl}_{4}\right)$ is expressed by the following equation ${ }^{4}: R_{\mathrm{p}}=$ const [IBVE] [Carbolac 1] $]^{2}$. It is known, however, that in the polymerization of styrene catalyzed by

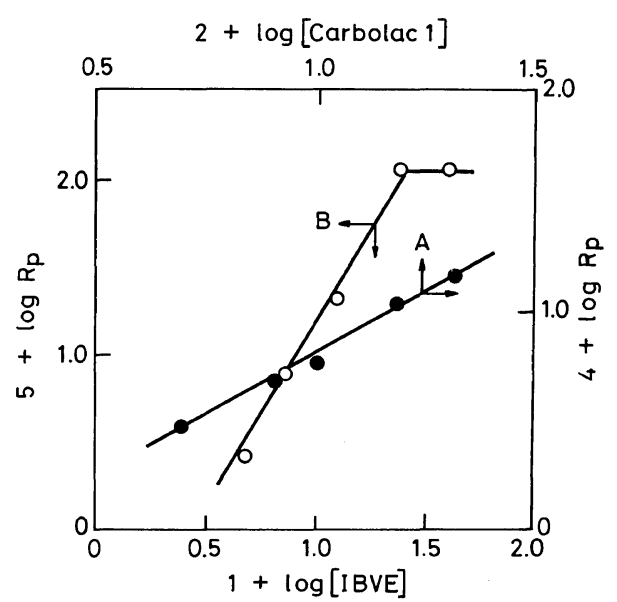

Figure 3. A: Dependence of $R_{\mathrm{p}}$ on the amount of Carbolac 1; IBVE, $3.8 \mathrm{moll}^{-1}$; solvent, $\mathrm{CCl}_{4} / \mathrm{C}_{6} \mathrm{H}_{5} \mathrm{NO}_{2}=50 \mathrm{v} / \mathrm{v} \%$; total volume, $20.0 \mathrm{ml} ; 20^{\circ} \mathrm{C}$. B: Dependence of $R_{\mathrm{p}}$ on the concentration of IBVE: Carbolac 1, $0.2 \mathrm{~g}$; solvent, $\mathrm{CCl}_{4} / \mathrm{C}_{6} \mathrm{H}_{5} \mathrm{NO}_{2}=50 \mathrm{v} / \mathrm{v} \%$; total volume, $20.0 \mathrm{ml} ; 20^{\circ} \mathrm{C}$.

carboxylic acid such as trichloroacetic acid, the kinetic order with respect to acid increases from unity to 3.5 as the dielectric constant of the medium is reduced from 31 to $2 .^{10}$

Thus, the polymerization of IBVE was carried out in a polar solvent $\left(\mathrm{CCl}_{4} / \mathrm{C}_{6} \mathrm{H}_{5} \mathrm{NO}_{2}=50 \mathrm{v} / \mathrm{v} \%\right)$ and the kinetic order with respect to carbon black in a polar solvent was compared with that in a nonpolar solvent.

Using $76 \mathrm{mmol}$ of IBVE and varied amounts of Carbolac 1, polymerization was carried out at $20^{\circ} \mathrm{C}$ and the results are shown in Figure 3-A. From the slope of the straight line, the rate of polymerization $\left(R_{\mathrm{p}}\right)$ can be expressed by,

$$
R_{\mathrm{p}}=\text { const [Carbolac 1] }
$$

The reaction order of concentration of IBVE was estimated by changing the concentration of IBVE. From the results shown in Figure $3-\mathrm{B}, R_{\mathrm{p}}$ can be expressed by,

$$
R_{\mathrm{p}}=\text { const }[\mathrm{IBVE}]^{2}
$$

Accordingly, it was found that the kinetic order with respect to the carbon black (namely the content of carboxyl groups) decreased from 2 to 1 with an increase of the dielectric constant of the solvent. A similar result was obtained in the bulk polymerization of NVPD: the kinetic order with respect to 
carbon black was unity. ${ }^{6}$ This may be interpreted as a respect of the large polarity of NVPD.

The phenomena above suggest that the initiating mechanism of the polymerization in a polar solvent is different from that in a nonpolar medium.

As mentioned in the previous paper, in a nonpolar solvent, it is considered that a pair of adjacent carboxyl groups plays an important role in the initiation of the polymerization. ${ }^{4}$ But in a polar solvent, the following mechanism is proposed, to explain the first order dependence on carbon black and the second order dependence on IBVE:

Initiation;

$$
\mathrm{CB}-\mathrm{COOH}+\mathrm{M} \stackrel{k_{\mathrm{i}}}{\longrightarrow} \mathrm{M}^{+}{ }^{-} \mathrm{CB}
$$

Propagation;

$$
\mathrm{M}_{n-1}^{+}{ }^{-} \mathrm{CB}+\mathrm{M} \stackrel{k_{\mathrm{p}}}{\longrightarrow} \mathrm{M}_{n}^{+}{ }^{-} \mathrm{CB}
$$

Termination;

$$
\begin{aligned}
& \mathrm{M}_{n}^{+}{ }^{-} \mathrm{CB} \\
& \mathrm{M}_{n}^{+}-\mathrm{CB}+\mathrm{M} \quad \stackrel{k_{\mathrm{m}}}{\longrightarrow} \mathrm{P} \\
& + \text { Unreactive CB }
\end{aligned}
$$

By the stationary state method, the following rate equation can be easily derived:

$$
R_{\mathrm{p}}=\frac{k_{\mathrm{p}} k_{\mathrm{i}}[\mathrm{CB}-\mathrm{COOH}][\mathrm{M}]^{2}}{k_{\mathrm{t}}+k_{\mathrm{m}}[\mathrm{M}]}
$$

Now if $k_{\mathrm{t}} \gg k_{\mathrm{m}}[\mathrm{M}]$, then

$$
R_{\mathrm{p}}=\frac{k_{\mathrm{p}} k_{\mathrm{i}}}{k_{\mathrm{t}}}[\mathrm{CB}-\mathrm{COOH}][\mathrm{M}]^{2}
$$

This is compatible with the actual experimental results. The assumption that the termination by monomer is relatively unimportant thus appears to be valid in the case of a polar solvent. ${ }^{11}$ On the other hand, in a nonpolar solvent, it is considered that $k_{\mathrm{m}}[\mathrm{M}]$ is much larger than $k_{\mathrm{t}}$, so that $R_{\mathrm{p}}$ is proportional to $[\mathrm{M}]$ as mentioned in the previous paper.

Figure 4 shows the effect of temperature on the polymerization of IBVE initiated by Carbolac 1 in a polar solvent. The overall activation energy was estimated to be $27 \mathrm{kcal} \mathrm{mol}^{-1}$. This value is larger than that for the polymerization of IBVE in $\mathrm{CCl}_{4}$ and that of the ordinary cationic polymerization.

\section{Grafting Sites on the Carbon Black Surface}

The carbon black obtained from the polymerization gave a stable colloidal dispersion in good

\begin{tabular}{|c|c|c|c|}
\hline \multirow{2}{*}{ Carbon black } & \multirow{2}{*}{$\frac{\mathrm{N}}{\%}$} & \multirow{2}{*}{$\begin{array}{l}\text { Poly(NVPD) retained } \\
\text { on the surface }\end{array}$} & \multirow{2}{*}{$\begin{array}{l}\text { Poly(NVPD) retained } \\
\text { after hydrolysis } \\
\mathrm{gg}^{-1}\end{array}$} \\
\hline & & & \\
\hline Untreated carbon black & 0.16 & - & - \\
\hline $\begin{array}{l}\text { Carbon black obtained } \\
\text { from polymerization }{ }^{\mathrm{a}} \\
\text { (Graft-carbon) }\end{array}$ & 2.37 & 0.21 & 0.13 \\
\hline $\begin{array}{l}\text { Carbon black obtained } \\
\text { from adsorption system }^{\mathrm{b}}\end{array}$ & 0.82 & 0.05 & 0.04 \\
\hline
\end{tabular}

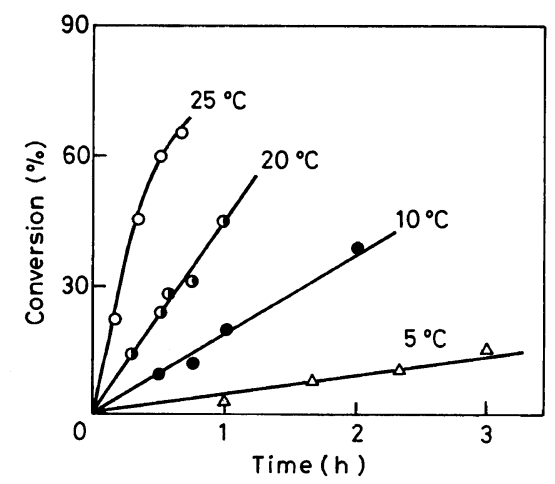

Figure 4. Temperature dependence of the polymerization of IBVE initiated by Carbolac 1 in polar solvent: Carbolac 1, 0.1 g; IBVE, $3.8 \mathrm{moll}^{-1}$; solvent, $\mathrm{CCl}_{4} / \mathrm{C}_{6} \mathrm{H}_{5} \mathrm{NO}_{2}=50 \mathrm{v} / \mathrm{v} \%$; total volume, $20.0 \mathrm{ml}$.

Table II. Poly(NVPD) grafted onto the surface of Neospectra II

a Neospectra II, $0.4 \mathrm{~g}$; NVPD, $20 \mathrm{ml} ; 30^{\circ} \mathrm{C} ; 24 \mathrm{~h}$.

b Neospectra II, $0.4 \mathrm{~g}$; poly(NVPD) $\left([\eta]=0.03 \mathrm{dl} \mathrm{g}{ }^{-1}, \mathrm{H}_{2} \mathrm{O}, 30^{\circ} \mathrm{C}\right), 5.0 \mathrm{~g}$; methanol, $20 \mathrm{ml}$.

c Poly(NVPD) grafted (adsorbed) Neospectra II, $0.5 \mathrm{~g} ; 10 \% \mathrm{NaOH}$ aqueous solution, $10 \mathrm{ml} ; 90^{\circ} \mathrm{C} ; 5 \mathrm{~h}$. 
solvents for the polymer. For example, the carbon black obtained in the polymerization of NVPD was dispersed in water and the precipitation of carbon black particles was not observed even after a period of one year. The phenomenon suggests that during polymerization, poly(NVPD) is grafted onto the carbon black surface.

By use of Neospectra II which has large specific surface area, the amount of poly(NVPD) grafted onto the surface was determined by a semi-microKjeldahl procedure ${ }^{7}$ and the results are shown in Table II. As is seen in Table II, Neospectra II obtained from the polymerization retained $0.21 \mathrm{~g}$ of poly(NVPD) per one gram of carbon black. The grafting efficiency was determined to be about $1 \%$. In contrast, the amount of poly(NVPD) adsorbed by Neospectra II from methanol solution was 0.05 $\mathrm{gg}^{-1}$. Therefore, it is clear that during the polymerization, poly(NVPD) was grafted onto the surface.

It has been reported that a reaction of NVC with an excess of acetic acid yields $N$-( $\alpha$-acetoxy)carbazole as the major product along with a mixture of oligomeric acetates. ${ }^{12}$ Accordingly, the grafting site of poly(NVPD) is presumed to be the carboxyl groups on the surface.

To clarify the location of the grafting sites, poly(NVPD) grafted carbon black was hydrolyzed by aqueous alkali and the result for this shown in Table II. The amount of poly(NVPD) grafted onto the surface decreased by the hydrolysis. In contrast, the amount of poly(NVPD) adsorbed by carbon black scarcely decreased by the hydrolysis. Then, in the case of other channel blacks, similar results were obtained.

In conclusion, in the present paper, it is found that carboxyl groups on the surface of channel blacks are able to initiate the cationic polymeri- zation of vinyl monomers such as vinyl ethers, indene, and acenaphthylene. Furthermore, during polymerization, the polymer was grafted onto the surface carboxyl groups as follows:

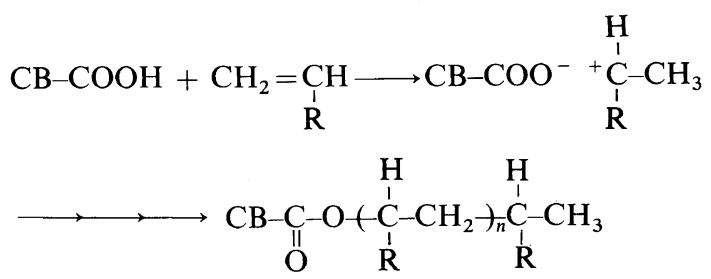

\section{REFERENCES}

1. P. H. Given and L. W. Hill, Carbon, 6, 525 (1968).

2. K. Ohkita, N. Tsubokawa, M. Noda, and M. Uchiyama, Carbon, 15, 194 (1977).

3. K. Ohkita, M. Uchiyama, and H. Nishioka, Carbon, 16, 195 (1978).

4. N. Tsubokawa, N. Takeda, and K. Kudoh, Nippon Kagaku Kaishi, 1264, (1980).

5. N. Tsubokawa, J. Polym. Sci., Polym. Lett. Ed., 18, 461 (1980).

6. N. Tsubokawa, N. Takeda, and A. Kanamaru, $J$. Polym. Sci., Polym. Lett. Ed., 18, 625 (1980).

7. K. Ohikita, T. Tsujita, and M. Maeda, Kobunshi Ronbunshu, 37, 343 (1980).

8. C. E. Schildknecht, A. O. Zoss, and F. Grosser, Ind. Eng. Chem., 41, 2891 (1949).

9. J. Brandrup, E. H. Immergut Ed., "Polymer Handbook," Interscience, New York, N.Y., 1966 p II-387.

10. C. P. Brown and A. R. Mathieson, J. Chem. Soc., 3631, (1957).

11. Y. Imanishi, T. Higashimura, and S. Okamura, Kobunshi Kagaku, 19, 154 (1962); Y. Imanishi, H. Nakayama, T. Higashimura, and S. Okamura, ibid, 19, 565 (1962).

12. A. Gandini and S. Prieto, J. Polym. Sci., Polym. Lett. Ed., 15, 337 (1977). 